\title{
Testing the Usability of the MediCare System
}

\section{Sarmad Monadel Sabree Al-Gayar ${ }^{a}$, Nicolae Goga ${ }^{b}$, Naseer Al-Habeeb,Haider ${ }^{\mathrm{c}}$ Abdullah Ali ${ }^{\mathrm{d}}$, Iuliana Marin $^{\mathrm{e}}$, Mohammed Safaa Shubber ${ }^{\mathrm{f}}$}

a, b, c,d,e University POLITEHNICA of Bucharest, Bucharest, Romania

b University of Groningen,Groningen, The Netherlands

${ }^{\mathrm{f}}$ Middle Technology University, College of Health and Medical Technology, Bab AlMoatham, Baghdad, Iraq

${ }^{\mathrm{a}}$ sarm.moon85@ gmail.com, ${ }^{\mathrm{b}}$ n.goga@ rug.nl, ${ }^{\mathrm{c}}$ naseeralhabeeb@gmail.com, ${ }^{\mathrm{d}}$ haider89.abdali@gmail.com,

emarin.iulliana25@gmail.com, ${ }^{\mathrm{f}} \mathrm{msm}$. shubber@gmail.com

Article History: Received: 10 November 2020; Revised 12 January 2021 Accepted: 27 January 2021; Published online: 5 April 2021

\begin{abstract}
Smartphones, digital medical devices, smart bracelets, and mobile applications have emerged in the healthcare field as an effective way to help in the treatment of patients. Healthcare services are characterized by ease of use, low cost, accessibility, mobility, and reliability. The MediCare system was built to enhance healthcare services in the Iraqi environment. The MediCare system can run on smartphones or tablets that operate on Android, but it can also be used as a web application. The research team wanted to evaluate if the platform meets customers' needs. Therefore, a usability survey for the MediCare system in regard to healthcare services and underlying technology was done. In this paper, an evaluation and usability measurement of the MediCare system is presented. The quantitative research shows that users found that the system is suitable for their needs. The system is especially necessary now, when the COVID-19 pandemic is a global emergency.
\end{abstract}

Keywords: Healthcare Usability Survey; wearable devices; social media.

\section{Introduction}

Emerging technologies and medical informatics provide major benefits to the medical field, in terms of usability, portability, reliability enhancement, non-intrusive control, monitoring of patients' vital signs, accuracy improvement, increase of efficiency, ease of accessibility and use. This, in turn, has helped health organizations to improve the quality of healthcare services provided [1]. In addition, the lower prices and advancements in the software and hardware capabilities of portable medical devices, bracelets, and smartphones, have contributed to a large expansion of the mobile devices and related technologies. Besides, modern smartphones and computers have greater computing power, contain GPS sensors, and provide permanent connectivity to the Internet and wireless networks [2]. This has led to the development of a large number of health applications over the last few years [3].

During the global expansion of mobile technology, the widespread use of Internet-enabled smartphones in the Iraqi community has increased dramatically as mobile applications became a key area of interest among physicians and patients in this environment [4]. Moreover, there is a certain number of applications in use by healthcare providers in Iraq with limited possibilities in regards to communication, monitoring or other functions of healthcare resulting in a trend for physicians and patients to opt for social media applications for fulfilling healthcare activities [5]. Medical professionals encourage Iraqi healthcare services to shift from their current reactive nature to a more proactive one with extensive support from technological solutions. Therefore, Iraqi health organizations seek to combine the efforts invested in the development of healthcare technologies with development in the health infrastructure in Iraq. Eventually, this should enable patient-centered healthcare providing better and faster health services for patients [6]. Due to the conditions and requirements of the Iraqi health environment, we developed a healthcare solution called "MediCare" which provides a social-media medical platform that facilitates interaction between numerous hospitals, clinics, physicians, and patients [24-26]. After the development of MediCare, it is of maximum importance to thoroughly verify its level of quality, satisfaction, and usability.

To get the expected advantages of healthcare technology, the MediCare system has to be beneficial and available for physicians and patients to improve patient safety and the quality of healthcare [9, 20-23]. A low level of usability in any healthcare system environment may be more worrisome, as issues regarding the usability may cause errors in medical diagnosis [10], by affecting the ability of physicians to perform tasks efficiently, and this may be related with patients' concerns regarding safety $[7,11]$. Besides, when users are unable to easily use, learn, and recognize the system tools with maximum effectiveness and minimum mistakes, a low level of usability can be indicated $[8,12,13]$. 
In this paper we report on a quantitative research that evaluates the use of MediCare. Since this MediCare platform links physicians and patients remotely, the questionnaire is intended to evaluate user interest of the system and the status of the interactions between physicians and patients inside the system such as appointments, quality of connection, easiness of completing a desired task with the provided user interfaces, and the overall impression of this medical social media system which targets the Iraqi environment [14].

The present paper is organized as follows: Section II presents the state-of-the-art. Section III describes the questionnaire and sampling. Section IV specifies the analysis of results. Finally, section V provides conclusions and research directions ahead.

\section{STATEOFTHEART}

In this section we describe the related work.

\section{A. Related Projects}

Concerning social media, there are social-media platforms with health-oriented purposes like PatientsLikeMe, HealthUnlocked and MedHelp. These are considered communication networks regarding healthcare and medical behaviour [15]. However, these solutions are not designed for mobile phones or do not work with smart bracelets and are not designed for Iraq.

\section{BeWell: A Smartphone Application to Monitor, Model and Promote Wellbeing}

BeWell is a personal health application that is designed specifically for smartphones to help people manage their overall health [16]. The application uses smartphones to monitor a person's physical activity automatically, social interaction, and sleep ways, also summarize the effect of the monitored behavior on healthcare and provide feedback that enables users to effectively manage these three key aspects of their health.

2. Human Activity Recognition on Smartphones Using a Multiclass Hardware-Friendly Support Vector Machine

This paper presents a system for human physical Activity Recognition (AR) using smartphone sensors [17]. Also, smartphones used for human activity recognition have potential applications in assisted living technologies. Considering current hardware limitations, a proposal is done for a new alternative for AR that requires less computational resources to operate. These sensors are built-in some smartphones by default and this system benefits from this to classify some physical activities (walking, standing, walking upstairs and walking downstairs, laying) by processing body signals through a supervised Machine Learning (ML) algorithm for hardware with limited resources.

\section{IoT-Based Information System for Healthcare Application: Design Methodology Approach}

The research proposes an Internet of Things (IoT) based health information system for outdoor and indoor use [18]. This implemented system utilizes the magnetometer and the three-axial accelerometer, Pedestrian Dead Reckoning (PDR), a decision trees algorithm, and thresholding. The architecture of this system enables with accuracy the position of a person within four room-zones. Furthermore, it identifies falls and activities like standing, laying, walking, and sitting. This system classifies current activities as dangerous, suspicious, or normal, based on the identified activities, which are utilized to notify the healthcare professionals about possible problems.

4. Mobile Healthcare Application with Electronic Medical Record (EMR) Interoperability for Diabetes Patients

This paper presents development of mobile healthcare application for the Android operating system to provide self-diabetes management [19]. This application contains of weight management, diabetes management, stress and depression evaluation, cardio-cerebrovascular risk evaluation, and exercise management. Also, this application synchronizes data with the registered hospital's EMR database to provide accurate data with a process of data input. This paper introduces a detailed structure and functionalities of the application, along with EMR data synchronization. Therefore, this application interfaces with the hospital's Electronic Medical Record system were developed to provide personalized services by analyzing the latest medical data from the considered EMR system.

Compared to our solution, the applications presented above do not work on computers, medical devices, and bracelets all together and do not provide medical posts. Thus, patients cannot communicate as on social media. Also, they do not target the Iraqi environment. The strengths and weaknesses of the proposed systems are shown in Table 1 below. 
TABLE I. RELATED PROJECTS

\begin{tabular}{|c|c|c|}
\hline $\begin{array}{c}\text { Closely } \\
\text { related } \\
\text { work }\end{array}$ & Strengths & Weaknesses \\
\hline $\begin{array}{l}\text { BeWell: A } \\
\text { Smartphon } \\
\text { e } \\
\text { Application } \\
\text { to Monitor, } \\
\text { Model and } \\
\text { Promote } \\
\text { Wellbeing }\end{array}$ & $\begin{array}{l}\text { 1. This application has the } \\
\text { potential to empower } \\
\text { individuals to improve } \\
\text { their overall wellbeing } \\
\text { and identify any early } \\
\text { signs of decline. } \\
\text { 2. This smartphone-based } \\
\text { system that can track } \\
\text { activities that impact } \\
\text { physical, social, and } \\
\text { mental wellbeing } \\
\text { namely, sleep, physical } \\
\text { activity, and social } \\
\text { interactions. } \\
\text { 3. The application } \\
\text { provides intelligent } \\
\text { feedback to promote } \\
\text { better health. }\end{array}$ & $\begin{array}{l}\text { 1. Does not work } \\
\text { with computers, } \\
\text { and medical } \\
\text { devices. } \\
\text { 2. The patients } \\
\text { cannot } \\
\text { communicate } \\
\text { between them } \\
\text { like in a social } \\
\text { network. } \\
\text { 3. Does not use } \\
\text { other health } \\
\text { activities for } \\
\text { tracking like } \\
\text { blood pressure, } \\
\text { heart rate. } \\
\text { 4. Does not support } \\
\text { feedback from } \\
\text { real doctors. }\end{array}$ \\
\hline $\begin{array}{l}\text { Human } \\
\text { Activity } \\
\text { Recognitio } \\
\mathrm{n} \text { on } \\
\text { Smartphon } \\
\text { es Using a } \\
\text { Multiclass } \\
\text { Hardware- } \\
\text { Friendly } \\
\text { Support } \\
\text { Vector } \\
\text { Machine }\end{array}$ & $\begin{array}{l}\text { 1. Aims to capture the } \\
\text { state of the user and its } \\
\text { environment by } \\
\text { exploiting } \\
\text { heterogeneous sensors } \\
\text { in order to provide } \\
\text { adaptation to exogenous } \\
\text { computing resources. } \\
\text { 2. When the sensors are } \\
\text { attached to the subject's } \\
\text { body, they permit } \\
\text { continuous monitoring } \\
\text { of numerous } \\
\text { physiological signals. } \\
\text { 3.Allows the exploitation } \\
\text { of Ambient Intelligence } \\
\text { (AmI) in daily activity } \\
\text { monitoring for elderly } \\
\text { people. }\end{array}$ & $\begin{array}{l}\text { 1. Does not work } \\
\text { with computers, } \\
\text { and medical } \\
\text { devices. } \\
\text { 2. The patients } \\
\text { cannot } \\
\text { communicate } \\
\text { between them } \\
\text { like in a social } \\
\text { network. } \\
\text { 3. Does not use } \\
\text { other health } \\
\text { activities for } \\
\text { tracking like } \\
\text { blood pressure, } \\
\text { heart rate. } \\
\text { 4. Does not support } \\
\text { communication } \\
\text { and appointment } \\
\text { with real doctors. }\end{array}$ \\
\hline $\begin{array}{l}\text { IoT-Based } \\
\text { Information } \\
\text { System for } \\
\text { Healthcare } \\
\text { Application } \\
: \quad \text { Design } \\
\text { Methodolo } \\
\text { gy } \\
\text { Approach }\end{array}$ & $\begin{array}{l}\text { 1. This system monitors } \\
\text { people's position and } \\
\text { their vital signs and can } \\
\text { distinguish different } \\
\text { activities and situations, } \\
\text { reacts accordingly to the } \\
\text { degree of danger and } \\
\text { alarms. } \\
\text { 2. Solves the problems of } \\
\text { real-life scenario of } \\
\text { supporting seniors }\end{array}$ & $\begin{array}{l}\text { 1. Does not work } \\
\text { with computers, } \\
\text { and medical } \\
\text { devices. } \\
\text { 2. The patients } \\
\text { cannot } \\
\text { communicate } \\
\text { between them } \\
\text { like in a social } \\
\text { network. } \\
\begin{array}{l}\text { 3. Does not use } \\
\text { other health } \\
\text { activities r for }\end{array}\end{array}$ \\
\hline
\end{tabular}




\begin{tabular}{|c|c|c|}
\hline $\begin{array}{l}\text { Closely } \\
\text { related }\end{array}$ & Strengths & Weaknesses \\
\hline & $\begin{array}{l}\text { living alone, especially } \\
\text { those with limited } \\
\text { abilities to manage their } \\
\text { daily lives. } \\
\text { 3. The achieved person's } \\
\text { localization accuracy } \\
\text { within one meter fits the } \\
\text { required four room-zone } \\
\text { level localization } \\
\text { accuracy in an } \\
\text { apartment environment. }\end{array}$ & $\begin{array}{l}\text { tracking like } \\
\text { blood pressure, } \\
\text { body } \\
\text { temperature. } \\
\text { 4. Does not support } \\
\text { communication } \\
\text { and appointment } \\
\text { with real doctors. }\end{array}$ \\
\hline $\begin{array}{l}\text { Mobile } \\
\text { Healthcare } \\
\text { Application } \\
\text { with } \\
\text { Electronic } \\
\text { Medical } \\
\text { Record } \\
\text { (EMR) } \\
\text { Interoperab } \\
\text { ility for } \\
\text { Diabetes } \\
\text { Patients }\end{array}$ & $\begin{array}{l}\text { 1. The process for data } \\
\text { input such as blood } \\
\text { sugar by patient is not } \\
\text { required. } \\
\text { 2.Supports patient } \\
\text { convenience and } \\
\text { increases the accuracy } \\
\text { of data and guidance for } \\
\text { diabetes management. } \\
\text { 3. Satisfies the patients' } \\
\text { right to know their } \\
\text { medical information. }\end{array}$ & $\begin{array}{l}\text { 1. The patients } \\
\text { cannot } \\
\text { communicate } \\
\text { between them } \\
\text { like in a social } \\
\text { network. } \\
\text { 2. Does not use } \\
\text { other health } \\
\text { activities for } \\
\text { tracking like } \\
\text { blood pressure, } \\
\text { body } \\
\text { temperature. } \\
\text { 3. Does not support } \\
\text { communication } \\
\text { and appointment } \\
\text { with real doctors. }\end{array}$ \\
\hline
\end{tabular}

\section{B. Description of the MediCare System}

Before describing the questionnaire and its results, we give bellow a short description of the evaluated system. A detailed description of the system is done in a previous published paper [24]. The Medical Social Media System (MediCare) has the following types of users:

- People/Patients, in search for a physician, asking for medical advice, read medical publications to enhance their medical culture and raise caution for disease avoidance, deliver the patient's health information and make an appointment with the physician. Furthermore, they can communicate with physicians through a mobile call, SMS, or instant message within MediCare platform, or by e-mails through the system.

- Physicians can monitor the health state of their patients. They can ask for health information, visualize their health logs, and offer medical advice for platform users. Physicians can read the most recent healthcare news and publish their medical advice.

The general architecture of the system is given in Figure 1. 


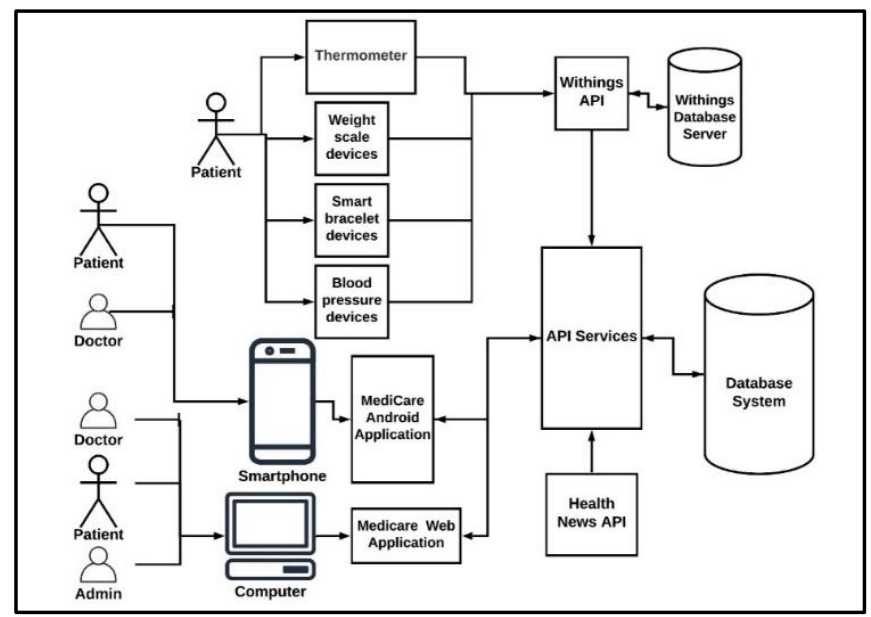

Figure 1. MediCare system architecture

The user can register by writing his/her data using a PC, a tablet, or a smartphone. The medical data is collected from patients by using different wearable devices, like smart bracelets. The system collects information from the user, such as heart rate and blood pressure measurements by adding wearable sensors or digital medical devices and stores information in the system's database, which can create medical reports for the user and offers the possibility to transmit the patient's medical data to the physician. The system enables physicians to monitor their patients' health status.

\section{Questionnaire And Sampling}

To determine the usability of the MediCare system and the efficiency of the user's interaction with the system, a questionnaire was created. The sampling method used was purposeful sampling and the questionnaire was distributed to the users, patients, and physicians to know their view regarding the system. A total of 30 persons answered the questionnaire.

The questionnaire was designed with respect to the users' point of view (patients and physicians) regarding the possibility of using the system, their evaluation of the system, the degree of their satisfaction with it and their interaction with it based on a period of two months usage of MediCare system. In total, there were 30 responders (persons from 37 to 78 years), out of which 4 physicians and 26 patients with different ages, academic graduations, and gender. The questionnaire was organized in the following way:

- The first category of questions focused on the background of the participants.

- The second category identified the extent of interaction with the MediCare platform.

- The last category of questions aimed to evaluate the usefulness of MediCare and the ability to use it in the healthcare process.

\section{A. Analysis of Results}

The first group of the questionnaire includes basic questions for users such as age (37 to 78 years), gender (63.3\% male and $36.7 \%$ female), specialization (10\% physician, $3.3 \%$ medical worker, and $86.7 \%$ user or patient) and education level ( $40 \%$ undergraduate, $43.3 \%$ bachelor, $16.7 \%$ postgraduate).

The users were divided per ages as groups for every 10 years (less than 40 years is $6.7 \%$, from $40-49$ is $23.3 \%$, from $50-59$ is $6.7 \%$, from $60-69$ is $36.7 \%$, and equal or more than 70 is $26.7 \%$ ), as in Figure 2. 


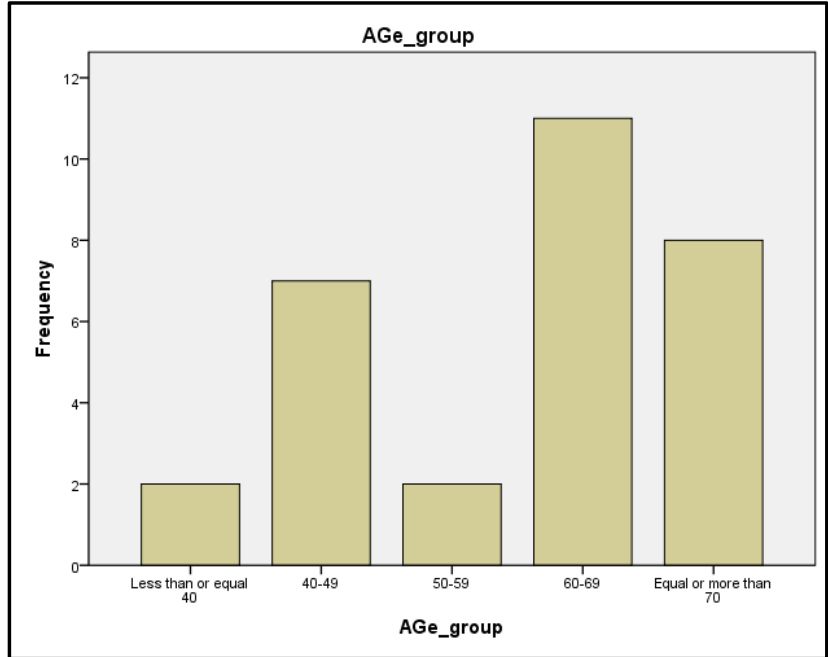

Figure 2. Age groups

The responders answered the question "Do you have special needs or are you suffering from a chronic disease?" with yes for $63.3 \%$ and $36.7 \%$ answered no, as in Figure 3. In addition, the persons who answered positively have diabetes, hypertension, or heart palpitations.

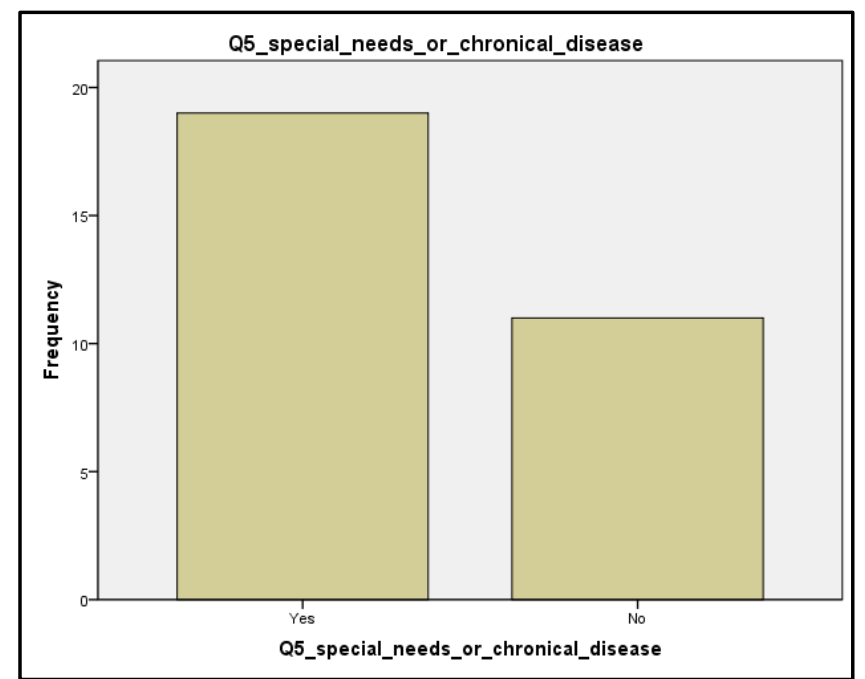

Figure 3. Users with special needs or who suffer from a chronical disease

The second group includes evaluating the degree of users' interest and their interaction with the MediCare system. The users answered this question: "Are you interested to use this health care application?" with yes by 96.7\% of the population and the remainder of 3.3\% answered no. The results can be seen in Figure 4.

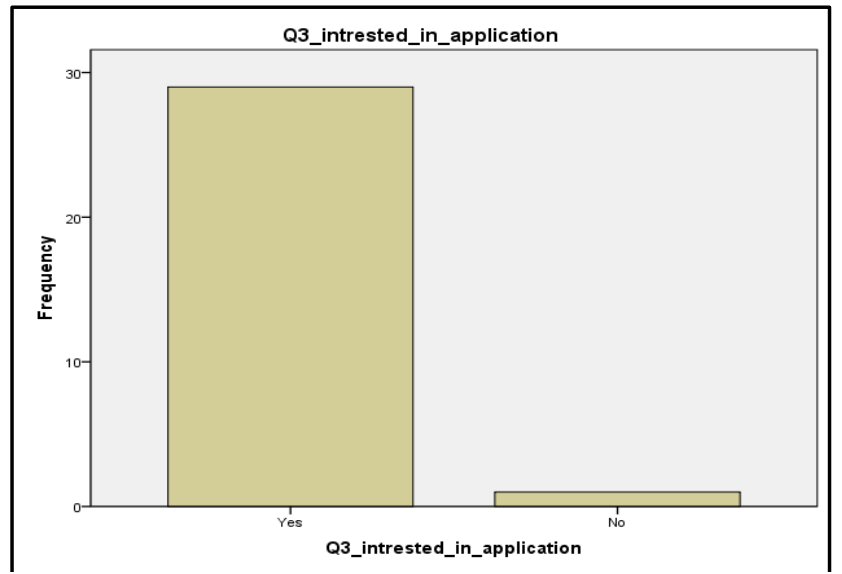

Figure 4. User interest regarding the MediCare application 
For the question "Do you think it's useful to send health data directly from a healthcare system to your physicians?", 96.7\% of the responders answered "Yes" and 3.3\% of them answered "No" (Figure 5). From the answers, it was observed that most of the users like to send their health data to their physicians through the proposed system.

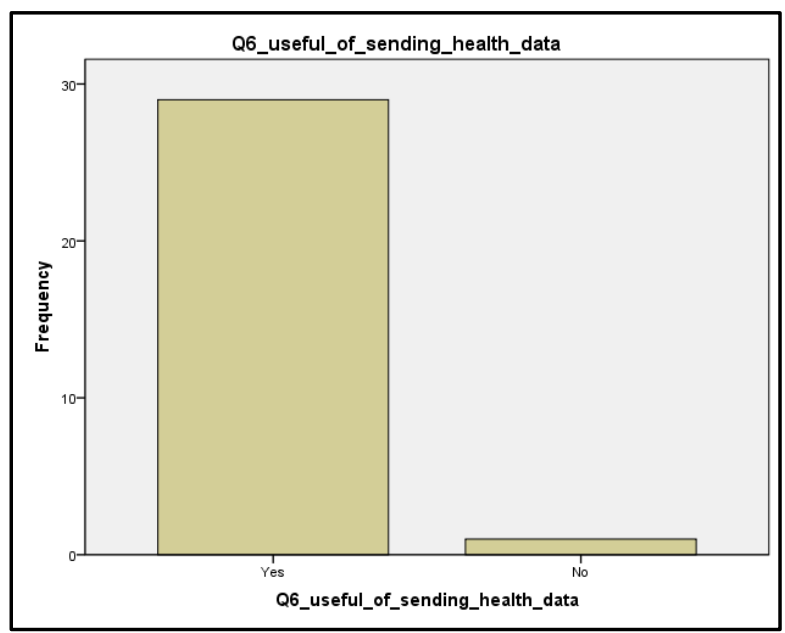

Figure 5. Sending health data directly from a healthcare system to physicians

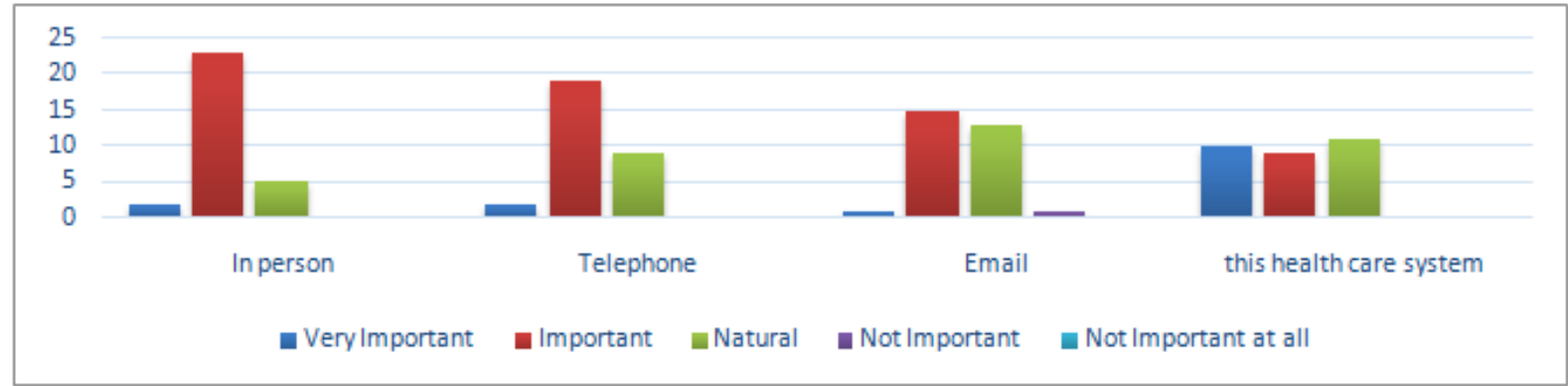

Figure 6. Communication between patients and physicians

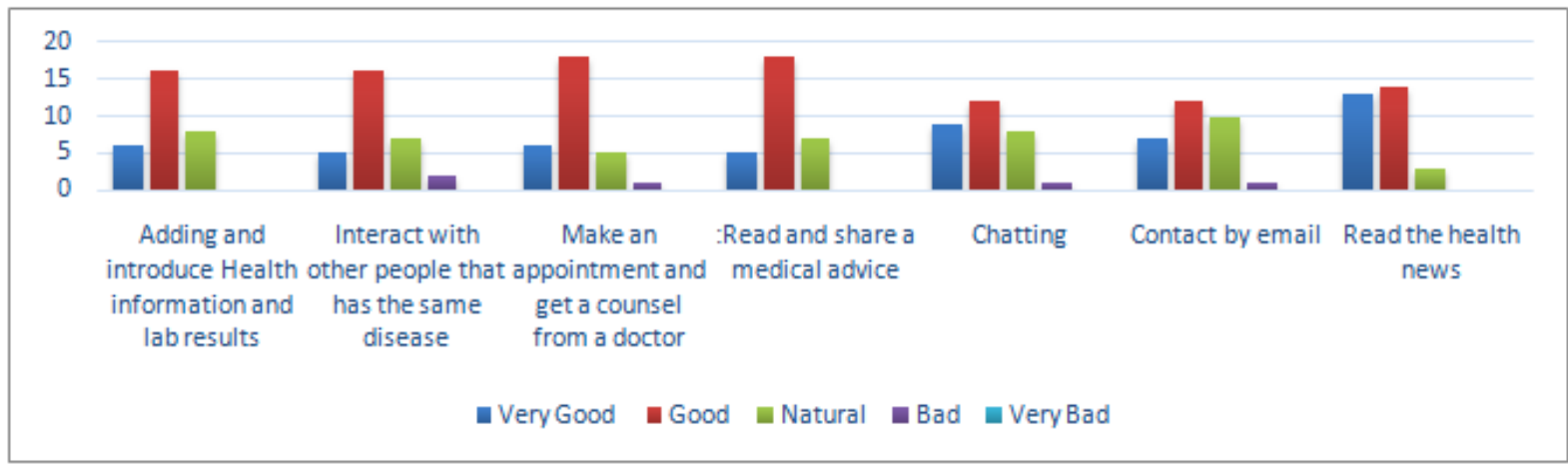

Figure 7. System features

For the question "How would you prefer the contact between physician and patient?", the answers are the following: 1 - In-person is 76.7\% 'Important' and 16.7\% 'Neutral'. 2 - 'Telephone' is 63.3\% 'Important' and 30.0\% 'Neutral'. 3 - 'Email' is 50.0\% 'Important' and 43.3\% 'Neutral'. 4 - 'this healthcare system' is 33.3\% 'Very Important', 30.0\% 'Important', and 36.7\% 'Neutral'. The detailed results are presented in Figure 6. From these answers, it was observed that most of the users prefer to communicate by using new technologies and especially the MediCare system.

For the question "How do you find the following features in this system?", the answers were centralized and illustrated in Figure 7. From these answers, it is observed that most of the users are interested in the features of MediCare system.

\section{B. MediCare Usability Evaluation}

The third category includes evaluating the usability of the system using the question: "Evaluating the usability of this system by selecting one from each group" based on usefulness, ease of use, ease of learning, satisfaction. 
The answers are illustrated in Figure 8 and they were the following: 1 - Usefulness, 30.0\% of participants choose "It is useful", while $23.3 \%$ choose "It meets my needs". 2 - Ease of Use, $50.0 \%$ of participants choose "It is easy to use", while $23.3 \%$ choose "It is user friendly". 3 - Ease of Learning, $40.0 \%$ of participants choose "I easily remember how to use it". 4 - Satisfaction, $73.3 \%$ of participants choose "I am satisfied with it".

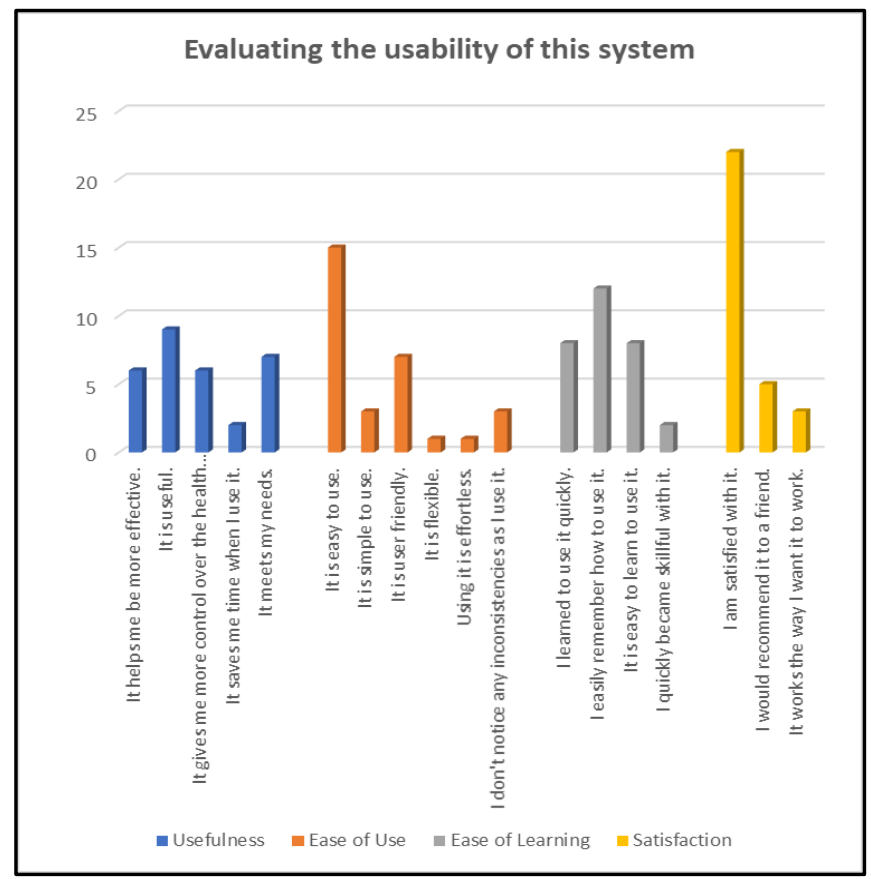

Figure 8. System usability evaluation

For the question "Choose one to evaluate the MediCare system usability", it was observed that most of the participants $(73.3 \%$ ) find that the system improves the quality of medical care provided, as in Figure 9.

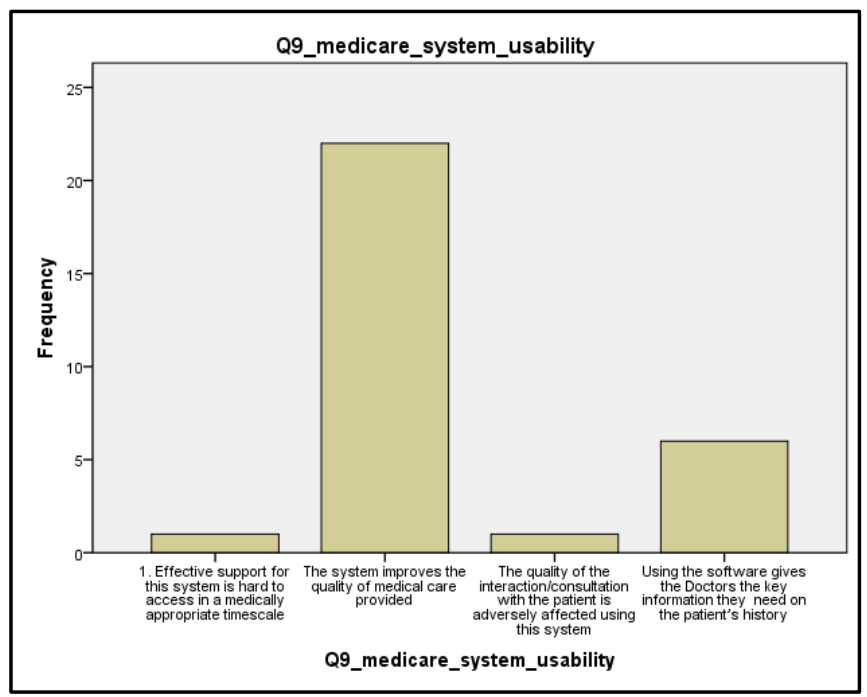

Figure 9. MediCare system evaluation

For the question "Please state your level of agreement or disagreement for the following statements based on your experience with the MediCare system", it was observed that most of the participants agree that the MediCare system s efficient, because $63.3 \%$ find the system efficient, $60.0 \%$ find the system interesting, and $66.7 \%$ find the system inventive. 


\section{Discussion}

Iraq is a developing country putting extensive efforts of modernization in medical technology in the last years. Healthcare has a positive effect on the work providing faster and easy access to medical services and, thus, enables healthcare professionals make better decisions. Also, the number of people using smart technologies is growing in Iraq, which increases their interaction with technology and helps them learn new techniques like smartphones, healthcare applications, smart bracelets, digital blood pressure devices and smart scales in a better manner. Therefore, it will be easy for patients and medical workers to use the MediCare platform which helps them achieve better success and growth in healthcare. Using MediCare increases efficiency at work helping patients interact with physicians in a better way.

The analysis of the Iraqi physicians' usability of the healthcare mobile applications reveals that physicians in Iraq use social media applications on their smartphones or computers and that they tend to use these applications frequently in their medical practice to help them make decisions regarding healthcare and facilitate the diagnosis process. On the other hand, regarding the users' interest in MediCare, it was concluded from the current study that the ease of use and usefulness of the system plays an important role in determining the intention of physicians and patients to use and adopt such a system in their healthcare practice.

There is a noticeable interest among the responders (about 92\%) concerning some features provided by the system. These are enumerated below in Table 2, considering the priority order for the users' desire and degree of satisfaction with the functions of the system:

TABLE II. LIST OF USABILITY RESULTS

\begin{tabular}{|c|c|c|}
\hline No & Most desired features & Optional desired features \\
\hline 1 & $\begin{array}{l}\text { Send health data } \\
\text { directly from a } \\
\text { healthcare system to the } \\
\text { physicians. }\end{array}$ & $\begin{array}{l}\text { Give physicians the } \\
\text { key information they } \\
\text { need regarding patient } \\
\text { history. }\end{array}$ \\
\hline 2 & \begin{tabular}{lr}
\multicolumn{1}{c}{ Contact } & between \\
physician and patient by \\
MediCare & system \\
(reliability). &
\end{tabular} & $\begin{array}{l}\text { Add and introduce } \\
\text { health information and } \\
\text { laboratory results. }\end{array}$ \\
\hline 3 & \begin{tabular}{lrr}
\multicolumn{1}{c}{ Make } & & an \\
appointment and & get \\
counsel from & a \\
physician. & &
\end{tabular} & $\begin{array}{l}\text { Interact with other } \\
\text { people who have the } \\
\text { same disease. }\end{array}$ \\
\hline 4 & Chat. & Meet user needs. \\
\hline 5 & $\begin{array}{l}\text { Read and share } \\
\text { medical advice. }\end{array}$ & $\begin{array}{l}\quad \text { Function properly } \\
\text { even at slow } \\
\text { speed. }\end{array}$ \\
\hline 6 & $\begin{array}{l}\text { Read the health } \\
\text { news. }\end{array}$ & \\
\hline 7 & Interested. & \\
\hline 8 & $\begin{array}{l}\text { Improve the } \\
\text { quality of the } \\
\text { provided medical } \\
\text { care (performance). }\end{array}$ & \\
\hline 9 & Usefulness. & \\
\hline 10 & Satisfaction. & \\
\hline 11 & Ease of use. & \\
\hline 12 & Efficiency. & \\
\hline
\end{tabular}

Overall, it can be concluded that users like the MediCare system. 


\section{Conclusions}

The current healthcare systems in Iraq have some usability obstacles that annoy users, such as the need for appropriate functionality, the necessity of flexibility and documentation. System usability issues can cause a waste of time in data entry, delays in displaying results and decrease system output and users' satisfaction. Therefore, health providers are determined to effectively improve the healthcare service usability for all beneficiaries. Developing MediCare is one of the efforts to enhance patients' user experience in healthcare services in Iraq. In addition, this system allows physicians, healthcare administrators and IT workers to provide valuable healthcare services in Iraq and facilitates interaction between physicians and patients. The current research aimed to make an overview of the effectiveness and usability of MediCare and the ability of physicians and patients to cooperate and interact with this healthcare platform. The targeted groups are medical workers in Iraq, patients and users who have an interest in medical treatment and advice.

In this paper, the results of a survey concerning the analysis of this medical social-media platform, MediCare, have been presented. It was observed that responders use healthcare applications in general. It was also observed that most physicians and patients consider that MediCare is useful because the system includes healthcare, diagnosis, and treatment aid. In addition, they can browse and display medical advice and share it.

In conclusion, physicians and patients agree that this system is good and can be used in their practice.

\section{Acknowledgment}

Special thanks to Assoc. Prof. PhD. Eng. Dan Gârlașu who has reviewed the current paper. He works as an Associate Professor at the Faculty of Engineering in Foreign Languages, University Politehnica of Bucharest, Romania.

\section{References}

Aqleh, M. M.; AL-Hashimi, M. S.; Hamdan, A.; Razzaque, A. Acceptance and Usability of Medical Informatics among Physicians. In International Conference e-Health 2019, Porto, Portugal, 17-19 July 2019; pp. 51-58.

Zhou, F. Mobile Personal Health Care System for Patients with Diabetes. Iowa State University, 2011.

Nayebi, F.; Desharnais, J.-M.; Abran, A. The State of the Art of Mobile Application Usability Evaluation. In Proceedings of the 25th IEEE Canadian Conference on Electrical and Computer Engineering (CCECE), Montreal, Canada, 29 April - 2 May 2012; pp. 1-4.

Durr, S. J.; Lotz-Sistika, H. Exploring the Social Learning Value Enabled by Affordances of the Food for Us Mobile Application: The Story of a South African Food Redistribution App. In Proceedings of the 15th International Conference Mobile Learning 2019, Utrecht, The Netherlands, 11-13 April 2019; pp. 1-8.

Zeki, S. M.; Rahma, A. M. S. Healthcare System Technology using Smart Phones and Web Apps (Case Study Iraqi Environment). I.J. Engineering and Manufacturing, 2017, 3, 1-7.

Kosiedowski, M.; Mazurek, C; Stroinski, A. Integration and Sharing of Personal Health Data as a Challenge for the Future Internet e-Health Scenarios. In Proceedings of the IADIS International Conference e-Health 2011, Rome, Italy, 20-22 July 2011; pp. 53-60.

Middleton, B.; Bloomrosen, M.; Dente, M. A.; Hashmat, B.; Koppel, R.; Overhage, J. M.; Payne, T. H.; Rosenbloom, S. T.; Weaver, C.; Zhang, J. Enhancing Patient Safety and Quality of Care by Improving the Usability of Electronic Health Record Systems: Recommendations from AMIA. J. Am. Med. Informatics Assoc., 2013, 20, 1-8.

Shneiderman, B. Tragic Errors: Usability and Electronic Health Records. Interactions, 2011, 18, 60-63.

Meehan, R. A.; Mon, D. T.; Kelly, K. M; Rocca, M.; Dickinson, G.; Ritter, J.; Johnson, C. M. Increasing EHR System Usability through Standards: Conformance Criteria in the HL7 EHR-System Functional Model. J. Biomed. Inform, 2016, 63, 169-173.

Kushniruk, A. W.; Triola, M. M.; Borycki, E. M.; Stein, B.; Kannry, J. L. Technology Induced Error and Usability: The Relationship between Usability Problems and Prescription Errors when Using a Handheld Application. Int. J. Med. Inform., 2005, 74, 519-526.

Lowry, S. Z.; Ramaiah, M.; Patterson, E. S.; Prettyman, S. S.; Simmons, D.; Brick, D.; Latkany, A. P.; Gibbons, M. C.; Taylor, S. L. NISTIR 7804-1: Technical Evaluation, Testing, and Validation of the Usability of Electronic Health Records: Empirically Based Use Cases for Validating Safety-Enhanced Usability and Guidelines for Standardization. In National Institute of Standards and Technology, 2015.

Usability 101: Introduction to Usability. Available online: https://www.nngroup.com/articles/usability-101introduction-to-usability/ (accessed on 7 July 2019).

Dias, C. R.; Pereira, M. R.; Freire, A. P. Qualitative Review of Usability Problems in Health Information Systems. J. Biomed. Inform., 2017, 76, 19-33.

Parmanto, B.; Lewis, A. N.; Graham, K. M.; Bertolet, M. H. Development of the Telehealth Usability Questionnaire. Int. J. Telerehabil, 2016, 8(1). 
Vasilateanu, A.; Casaru, C. Anonimity in Health-Oriented Social Networks. In ScienceDirect Procedia Computer Science,2015, 64, pp. 483-490.

Lane, N. D.; Mohammod, M.; Lin, M.; Yang, X.; Lu, H.; Ali, S.; Doryab, A.; Berke, E.; Coudhury, T.; Campbell, A. T. BeWell: A Smartphone Application to Monitor, Model and Promote Wellbeing. In Proceedings of the 5th International ICST Conference on Pervasive Computing Technologies for Healthcare, Dublin, Republic of Ireland, 23-26 May 2011; pp. 1-8.

Anguita, D.; Ghio, A.; Oneto, L.; Parra, X.; Reyes-Ortiz, J. L. Human Activity Recognition on Smartphones Using a Multiclass Hardware-Friendly Support Vector Machine. Ambient Assisted Living and Home Care. IWAAL 2012. Lecture Notes in Computer Science, Springer, Berlin, Germany, 2012; Volume 7657, pp. 216223.

Dziak, D.; Jachimczyk, B.; Kulesza, W. J.; IoT-Based Information System for Healthcare Application: Design Methodology Approach. Appl. Sci,2017, 7(6), pp. 1-26.

Jung, E.-Y.; Kim, J.; Chung, K.-Y.; Park, D. K. Mobile Healthcare Application with EMR Interoperability for Diabetes Patients. Cruster Computing, 2014, 17, pp. 871-880.

Ryu, Y. S. Development of Usability Questionnaires for Electronic Mobile Products and Decision Making Methods. Dissertation Submitted to the Faculty of Virginia Polytechnic Institute and State University in Partial Fulfillment of the Requirements for the Degree of Doctor of Philosophy in Industrial and Systems Engineering, 2005.

Gafni, R. Usability Issues in Mobile-Wireless Information Systems. Journal of Issues in Informing Science and Information Technology, 2009, 6, pp. 755-769.

Zhang, D.; Adipat, B. Challenges, Methodologies, and Issues in the Usability Testing of Mobile Applications. Int. J. Hum. Comput. Interact., 2005, 18(3), pp. 293-308.

Lima, V.; Talhi, C.; Mouheb, D.; Debbabi, M.; Wang, L.; Pourzandi, M., Formal Verification and Validation of UML Sequence Diagrams using Source and Destination of Messages. Electronic Notes in Theoretical Computer Science, 2009, 254, pp. 143-160.

Al-Gayar, S. M. S,; Marin, I.; Almalchy, M.; Goga, N.; Al-Habeeb, N.; Taslitschi, C., Implementation of MediCare Social Media System. In Proceedings of the 12th International Conference on Electronics, Computers and Artificial Intelligence (ECAI), Bucharest, Romania, 25-27 June 2020, pp. 1-8.

Al-Gayar, S. M. S;. Goga, N.; Al-Habeeb, N. A. J., Promela and Spin Formal Verification of an M-Health Medical Social Media System. In Proceedings of the International Conference on Automation, Computational and Technology Management (ICACTM), London, United Kingdom, 24-26 April 2019, pp. 511-517.

Al-Gayar, S. M. S.; Goga, N.; Hassoon, I. A.; Almalchy, M. T. Q., Medical Social Media Systems Implementation of the Android Application. In Proceedings of the 11th International Conference on Electronics, Computers and Artificial Intelligence (ECAI), Pitesti, Romania, 27-29 June 2019, pp. 1-6. 